\title{
Arabinogalactan-Proteins Reacting with Eel Anti-H Agglutinin from Leaves of Cruciferous Plants
}

\author{
Kazuo Nakamura, Yoichi Tsumuraya, Yohichi Hashimoto \\ and Shigeru YAMAмOTO* \\ Department of Biochemistry, Faculty of Science, Saitama University, \\ 255 Shimo-okubo, Urawa 338, Japan \\ *Laboratory of Serology and Biochemistry, National Research Institute \\ of Police Science, 6 Sanban-cho, \\ Chiyoda-ku, Tokyo 102, Japan
}

Received September 9, 1983

\begin{abstract}
Glycoconjugates reacting with eel anti-H agglutinin were purified from extracts of leaves of three species of cruciferous plants (radish, turnip, and rape) by precipitation with ethanol, ionexchange chromatography, and gel filtration. High voltage paper electrophoresis or ultracentrifugal analysis revealed that the purified specimens were homogeneous. Their apparent molecular weights were estimated to range from 0.5 to $1.5 \times 10^{5}$. They consisted of a novel L-fucose-containing acidic arabinogalactan-protein composed of residues of L-arabinose, D-galactose, L-fucose, 4- $O$-methyl-Dglucuronic acid, and D-glucuronic acid in similar molar proportions, and containing polypeptide portions with abundant hydroxyproline, serine, threonine, and alanine. All the arabinogalactanproteins exhibited potent inhibitory activity against the hemagglutination of human $\mathrm{O}$ erythrocytes by eel anti-H agglutinin.
\end{abstract}

Blood group $\mathrm{H}$-active substances in higher plants were first reported by Springer et al., who found complex polysaccharides with potent inhibitory activities against the hemagglutination of human $\mathrm{O}$ erythrocytes by anti-H agglutinin from eel serum in water-soluble fractions from twigs of the Japanese yew, Taxus cuspidata, and of Sassafras albidum. ${ }^{1 \sim 3)}$ Their respective immunodeterminants for the blood group $\mathrm{H}$-active specificity were shown to be 2-O-methyl-L-fucosyl and 3-O-methyl-Dgalactosyl residues. Recently, Yamamoto presented serological data demonstrating a wide distribution of substances with blood group A-, B-, and H-like activities in leaves, seeds, and fruits of a variety of wild plants, vegetable foods, and fruit bodies of edible mushrooms. ${ }^{4 \sim 7)}$ It was also postulated that rosaceous seeds and leaves of cruciferous plants such as the radish, turnip, and cabbage represent promising candidates as sources of $\mathrm{H}$-like substances. ${ }^{8)}$ This paper describes the purification procedures and chemical and serologi- cal properties of L-fucose-containing acidic arabinogalactan-proteins (AGPs) from leaves of three species of cruciferous plants, the radish, turnip, and rape.

\section{EXPERIMENTAL}

Materials. Fresh mature leaves of a cultivar, Aokubi, of the radish, Raphanus sativus L. var. hortensis Backer, and a cultivar, Kanamachi, of the turnip, Brassica Rapa L. var. glabra Kitam., were purchased from a farm and a local green grocery, respectively. Leaves of the rape, Brassica campestris L. subsp. Napus Hook., grown in an experimental field were harvested in early June. DEAE-cellulose was a product of the Brown Co., Berlin, New Hampshire, U.S.A. Sepharose 6B, Sepharose CL-6B, and FITC-dextrans were purchased from Pharmacia Japan, Tokyo. Whatman No. 1 and $3 \mathrm{MM}$ filter papers were obtained from the Whatman Ltd., England. Glass fiber paper GA-100 and silica gel 60F 254 plates were obtained from the Toyo-Roshi Co., Tokyo and the Merck Co., West-Germany, respectively. Pork liver L-fucose dehydrogenase was prepared by the method of Schachter et al. ${ }^{9)}$

General analytical methods. Deionization was accom- 
plished with a short column of Dowex $50 \mathrm{~W}\left(\mathrm{H}^{+}\right)$resin, or a column of mixed Dowex 50W $\left(\mathrm{H}^{+}\right)$and $1\left(\mathrm{HCO}_{3}{ }^{-}\right)$ resins. Total sugars were estimated by the phenol-sulfuric acid method ${ }^{10)}$ using a mixture of L-fucose, L-arabinose, and D-galactose in the ratio (w/v) of 5:30:65 as the standard. The estimation of uronic acid was made by a modified carbazole-sulfuric acid method, ${ }^{11)}$ employing Dglucuronic acid as the standard. The determination and identification of $\mathrm{L}$-fucose were carried out by a spectrometric method with pork liver $L$-fucose dehydrogenase. ${ }^{9)}$ Total nitrogen content was determined by the micro-Kjeldahl method. Protein content was estimated by the method of Lowry et al. ${ }^{12)}$ using bovine serum albumin as the standard.

Qualitative analysis of monosaccharides was performed by paper chromatography (PC) on Whatman No. 1 and $3 \mathrm{MM}$ papers in two solvent systems: A, n-butanolpyridine-water $(6: 4: 3, \mathrm{v} / \mathrm{v} / \mathrm{v})$ and $\mathrm{B}$, the upper layer of $n$ butanol-acetic acid-water $(4: 1: 5, \mathrm{v} / \mathrm{v} / \mathrm{v})$ in descending development. The spots of sugars on the chromatograms were visualized with alkaline silver nitrate ${ }^{13)}$ and $p$ anisidine hydrochloride reagent. ${ }^{14)}$ Paper electrophoresis was conducted on Whatman $3 \mathrm{MM}$ paper with $0.1 \mathrm{M}$

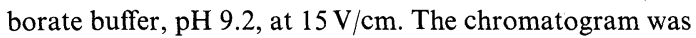
dipped in $1 \%$ acetic acid in methanol before detection with alkaline silver nitrate reagent. In high voltage electrophoresis, the purified AGPs were run on a sheet of GA-100 $(10 \times 30 \mathrm{~cm})$ with a buffer of pyridine-acetic acid-water, $3: 1: 387, \mathrm{v} / \mathrm{v} / \mathrm{v}, \mathrm{pH} 5.4$, at $4,000 \mathrm{~V}$ for $40 \mathrm{~min}$ or with $60 \mathrm{~mm}$ borate buffer, $\mathrm{pH} 9.5$, at $1,500 \mathrm{~V}$ for $30 \mathrm{~min}$ at $4^{\circ} \mathrm{C}$. Following the runs, the glass fiber papers were air-dried, cut into small strips $(0.7 \times 1 \mathrm{~cm})$ and eluted with distilled water. Aliquots of each eluate were assayed for sugars, protein, and the hemagglutination inhibition activity. For the gas liquid chromatographic (GLC) analysis of monosaccharide constituents, aliquots $(2 \mathrm{mg})$ of the samples were hydrolyzed with $\mathrm{M}$ sulfuric acid for $4 \mathrm{hr}$ at $100^{\circ} \mathrm{C}$, followed by neutralization with $\mathrm{BaCO}_{3}$ and desalting. The hydrolyzates were reduced with $\mathrm{NaBH}_{4}$ and acetylated by heating with acetic anhydride and pyridine $(0.2 \mathrm{ml}, 1: 1$, $\mathrm{v} / \mathrm{v}$ ) for $2 \mathrm{hr}$ at $100^{\circ} \mathrm{C}$. The alditol acetate derivatives were separated using a Shimadzu GC-5AM gas chromatograph equipped with a flame ionization detector and fitted with a glass column $(3 \mathrm{~mm} \times 2 \mathrm{~m})$ containing $3 \%$ ECNSS-M on Gaschrom Q at $190^{\circ} \mathrm{C}$. For GLC-MS, a JEOL D-300 mass spectrometer with columns $(3 \mathrm{~mm} \times 1 \mathrm{~m})$ packed with $3 \%$ ECNSS-M or $3 \%$ silicone OV-17 on Chromosorb W AWDMCS, was employed. The ${ }^{1} \mathrm{H}-\mathrm{NMR}$ spectrum was recorded on a JEOL-FX270 (270-MHz) instrument, with $\mathrm{D}_{2} \mathrm{O}$ as solvent and sodium 2,2-dimethyl-2-silapentane-5sulfonate as the internal standard at $80^{\circ} \mathrm{C}$.

To determine the amino acid composition, aliquots (10 mg) of the AGPs were hydrolyzed with $6 \mathrm{M} \mathrm{HCl}$ in sealed tubes for $20 \mathrm{hr}$ at $110^{\circ} \mathrm{C}$. After evacuation of the $\mathrm{HCl}$ in vacuo, amino acids were estimated with a Hitachi KLA5 amino acid analyzer. The content of hydroxyproline in the hydrolyzates was determined by the colorimetric method of Blumenkrantz et al. ${ }^{15)}$ Hydroxyproline was also identified by TLC on a silica gel $60 \mathrm{~F} 254$ plate with a solvent system of $n$-propanol-water $(7: 3, v / v)$. The spot of hydroxyproline was located with isatin-ninhydrin reagent. ${ }^{16)}$

Apparent molecular weights of the AGPs were estimated by measurement of the elution volumes on a calibrated Sepharose CL-6B column $(1 \times 85 \mathrm{~cm})$ equilibrated with $0.0145 \mathrm{M}$ phosphate buffer, $\mathrm{pH} 7.2$, containing $0.13 \mathrm{M} \mathrm{NaCl}$ and $0.02 \% \mathrm{NaN}_{3}$ (PBSN). FITC-dextrans $150,70,40$, and 20 were used as molecular markers. The sedimentation coefficients of the AGPs were calculated after analysis in a Hitachi-Beckman Model E analytical centrifuge at $60,000 \mathrm{rpm} 40 \mathrm{~min}$ at $20^{\circ} \mathrm{C}$.

Serological methods. Japanese eels, Anguilla japonica, were bled by dissecting their tails to provide sera, from which anti-H agglutinin was selected with regard to high titer and specificities. ${ }^{4)}$ Chicken antisera against human $\mathrm{O}$ erythrocytes and a partially purified anti-H lectin from seeds of Ulex europeus were obtained by the procedures reported previously. ${ }^{4)}$ The blood group $\mathrm{H}$ activity was assayed by the hemagglutination inhibition technique using serial 2-fold dilutions $(25 \mu \mathrm{l})$ of $\mathrm{H}$-active material in $0.85 \% \mathrm{NaCl}$ (saline) plus a constant amount ( $25 \mu \mathrm{l})$ of prediluted (titer $1: 8)$ eel anti-H agglutinin. After standing for $2 \mathrm{hr}$ at $4{ }^{\circ} \mathrm{C}$, the hemagglutination inhibition activity was determined by the addition of $2 \%$ human $\mathrm{O}$ erythrocytes in saline $(25 \mu \mathrm{l})$. The activity was expressed as the minimum concentration $(\mu \mathrm{g} / \mathrm{ml})$ of the material causing observable inhibition of hemaglutination, or as the reciprocal, expressed as $2^{n}$, of the lowest dilution to inhibit hemagglutination, ${ }^{4)}$ under these conditions, standard Lfucose required about $200 \mu \mathrm{g} / \mathrm{ml}$ as the minimum concentration causing hemagglutination inhibition.

Extraction and purification of AGPs. Fresh mature radish leaves were washed with water, blotted, excised of their midribs, dissected into small pieces and disintegrated with 3 times their weight of PBSN in a blender for $15 \mathrm{~min}$. The resultant homogenates were heated in a boiling water bath with occasional shaking for $30 \mathrm{~min}$, cooled and filtered through a double layer of Toyo-Roshi No. 2 filter paper on a Buchner funnel to remove insoluble residues. To the clear tan filtrate, 2.5 volumes of ethanol were added. The mixture was shaken vigorously and left standing overnight at $4^{\circ} \mathrm{C}$ for the sediments to settle. These sediments were then collected by centrifugation at $12,000 \times g$ for $20 \mathrm{~min}$ and suspended in 10 volumes of distilled water. After extraction at $4^{\circ} \mathrm{C}$ by mechanical stirring for $10 \mathrm{hr}$, the insoluble materials were removed by centrifugation. The resultant supernatant was dialyzed against several changes of distilled water and lyophilized to give a light tan powder.

This crude polysaccharide fraction was dissolved in water and fractionated on a column $(2.7 \times 35 \mathrm{~cm})$ of DEAE-cellulose $\left(\mathrm{HCO}_{3}\right.$-form). After the column had been 
washed with water, the adsorbed polysaccharides were eluted by a linear gradient $(0 \sim 0.5 \mathrm{M})$ of $\mathrm{NaHCO}_{3}$, resulting in partial resolution of the AGPs reacting with eel anti$\mathrm{H}$ agglutinin into two components. The fractions were combined, dialyzed, and lyophilized. Each sample of the resolved AGPs was then dissolved in PBSN and filtered through a PBSN-equilibrated column $(4 \times 100 \mathrm{~cm})$ of Sepharose 6B. After elution with PBSN, the polysaccharide fractions with hemagglutination inhibition activity were pooled, dialyzed, and lyophilized. Finally, highly purified AGPs, termed R-I and R-II, were obtained by subsequent rechromatography of each gel-filtered component on a DEAE-cellulose column under the same conditions as for the initial DEAE-cellulose column chromatography. Essentially the same procedure as above was effectively applied for the separation and purification of the AGPs having serological activity in crude polysaccharide fractions from turnip and rape leaves.

Isolation of sugar constituents of the AGPs. The acid hydrolyzates of the combined purified radish leaf AGPs RI and R-II ( $300 \mathrm{mg})$ were brought to $\mathrm{pH} 7$ and applied to a column $(2 \times 15 \mathrm{~cm})$ of Dowex $1\left(\mathrm{HCOO}^{-}\right)$. The effluent after washing with distilled water was saved for analysis of the neutral sugar components. The column was successively eluted with a linear gradient of 0 to $2 \mathrm{M}$ formic acid. A single peak ( $32 \mathrm{mg}$ ), which was, however, observed to contain several acidic components including aldobiouronic acid, was pooled and concentrated. The neutral and acidic components were further separated by preparative PC and characterized.

\section{RESULTS}

\section{Purification of AGPs reacting with eel anti- $H$ agglutinin}

L-Fucose-containing AGPs were readily extracted with hot PBSN from leaves of radish, turnip, and rape. The AGPs could be fractionated on a column of DEAE-cellulose $\left(\mathrm{HCO}_{3}{ }^{-}\right.$form), depending on their uronic acid contents. For instance, as depicted in Fig. 1, the acidic AGPs from radish leaves were partially resolved into two serologically active components, termed R-I and R-II. After gel filtration on a Sepharose $6 \mathrm{~B}$ column, each component was subsequently subjected to rechromatography on a DEAE-cellulose column, in which the peak of hemagglutination inhibition activity was apparently coincident with those of carbohydrate and protein in both R-I and R-II. The same procedure was effectively utilized for the preparation of L-fucosecontaining AGPs from leaves of turnip and

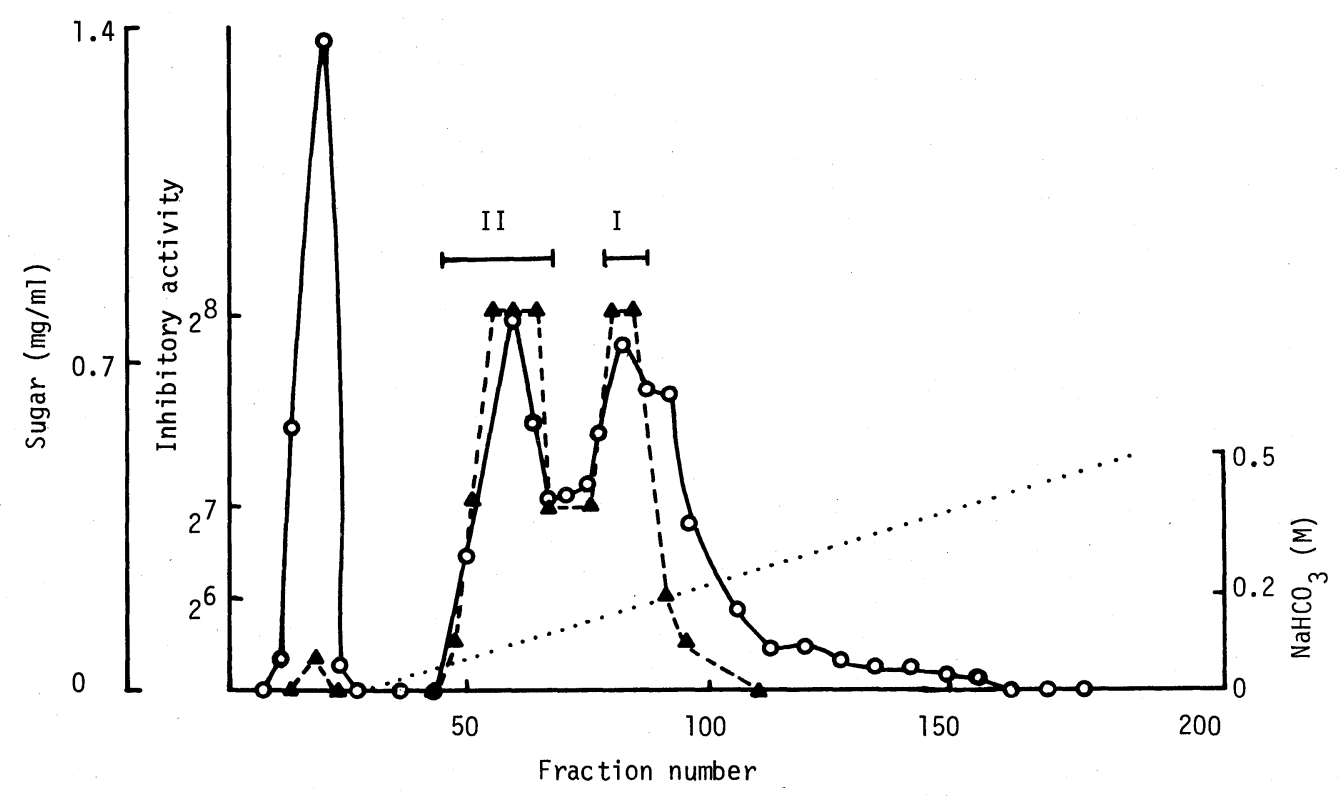

FIG. 1. Separation of Two AGPs by DEAE-Cellulose Column Chromatography.

A crude polysaccharide fraction $(3 \mathrm{~g})$ from radish leaves was subjected to chromatography on a DEAEcellulose $\left(\mathrm{HCO}_{3}{ }^{-}\right.$form $)$column. Fractions of $10 \mathrm{ml}$ each were collected. $\bigcirc-\bigcirc$, sugar; $\boldsymbol{\Delta}$------ $\boldsymbol{\Delta}$, serological activity; -----, $\mathrm{NaHCO}_{3}$. Fractions were pooled as indicated (-). 
Table I. Purification of AGPs Reacting with Eel Anti-H Agglutinin From Leaf Tissues of Cruciferous Plants

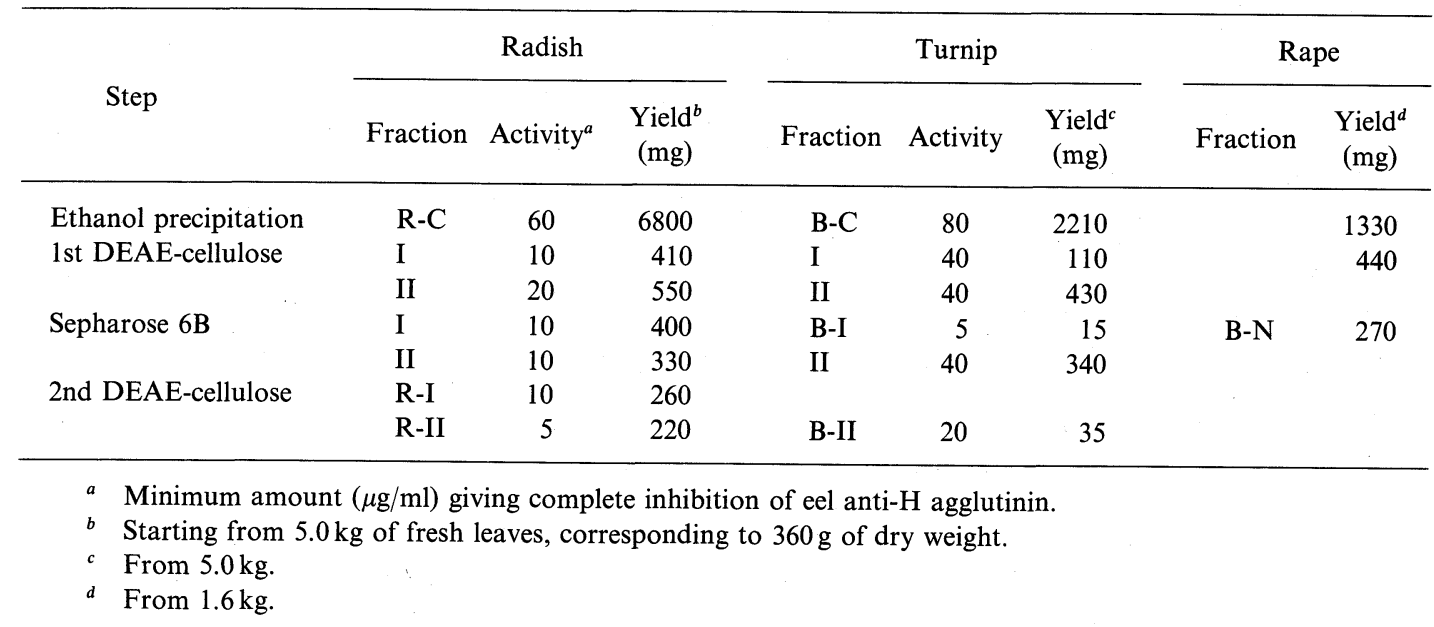

rape. Unlike the radish leaf AGPs, one broad polysaccharide peak, termed B-I, was detected in the unadsorbed fractions on DEAEcellulose in the turnip crude polysaccharide fraction, while the other component, termed B-II, was adsorbed and eluted from the column by linear gradient elution with $\mathrm{NaHCO}_{3}$. From the rape polysaccharide fraction, a $\mathrm{L}^{-}$ fucose-containing acidic AGP, termed B-N, was obtained through column chromatography on DEAE-cellulose. Table I summarizes the yields and hemagglutination inhibition activities during purification of the leaf AGPs of these three species of cruciferous plants.

Criteria for the homogeneity of the AGPs were provided by high voltage paper electrophoresis on glass fiber paper and ultracentrifugal analysis. Figures $2 \mathrm{~A}$ and $\mathrm{B}$ depict electrophoretic patterns after runs of the two radish AGPs, R-I, and R-II, with the buffer system at $\mathrm{pH} 9.5$, in which a single polysaccharide peak of either R-I or R-II was obtained which explicitly coincided with that of the hemagglutination inhibition activity and protein. In an acidic buffer system, $\mathrm{pH}$ 5.4, a single polysaccharide peak for each sample was obtained. The sedimentation patterns of R-I and R-II, shown as insets in Fig. 2, provided further evidence that these radish AGPs were apparently homogeneous. The homogeneity of the rape specimen was confirmed by the same procedures.

Identification of sugar constituents of the AGPS Identification of the isolated neutral monosaccharides was achieved by examination of their chromatographic behavior on P.C., mobility on electrophoresis, and specific rotation. This indicated the presence of three sugars: L-fucose, L-arabinose, and Dgalactose. Identification of $\mathrm{L}$-fucose was also confirmed by the action of L-fucose dehydrogenase, which resulted in the complete disappearance of the monosaccharide corresponding to L-fucose.

One of the isolated uronic acid components ( $2 \mathrm{mg}$, a minor component), having $R_{\mathrm{Glc}} 0.53$ on $\mathrm{PC}$ with solvent $\mathrm{B}$, was reduced with $\mathrm{NaBH}_{4}$, esterified at its carboxyl group by heating with Dowex 50W $\left(\mathrm{H}^{+}\right)$in dry methanol $(1 \mathrm{ml})$ for $2 \mathrm{hr}$ at $100^{\circ} \mathrm{C}$, reduced $\left(\mathrm{NaBH}_{4}\right)$ to the corresponding alditol, and acetylated by heating with acetic anhydride and pyridine. ${ }^{17)}$ Its GLC analysis yielded a single peak corresponding to glucitol acetate. On evaluation of its specific rotation, the uronic acid was identified as D-glucuronic acid. The other uronic acid (11 mg, a major component) gave $R_{\mathrm{Glc}} 0.70$ with solvent $\mathrm{B}, M_{\mathrm{Glc}}$ $0.96,[\alpha]_{\mathrm{D}}^{20}+32^{\circ}(c=0.25$, water $)$, and a strong signal at $\delta 3.48(3 \mathrm{H})$ on its NMR spectrum, indicating the presence of an $O$-methyl group, 

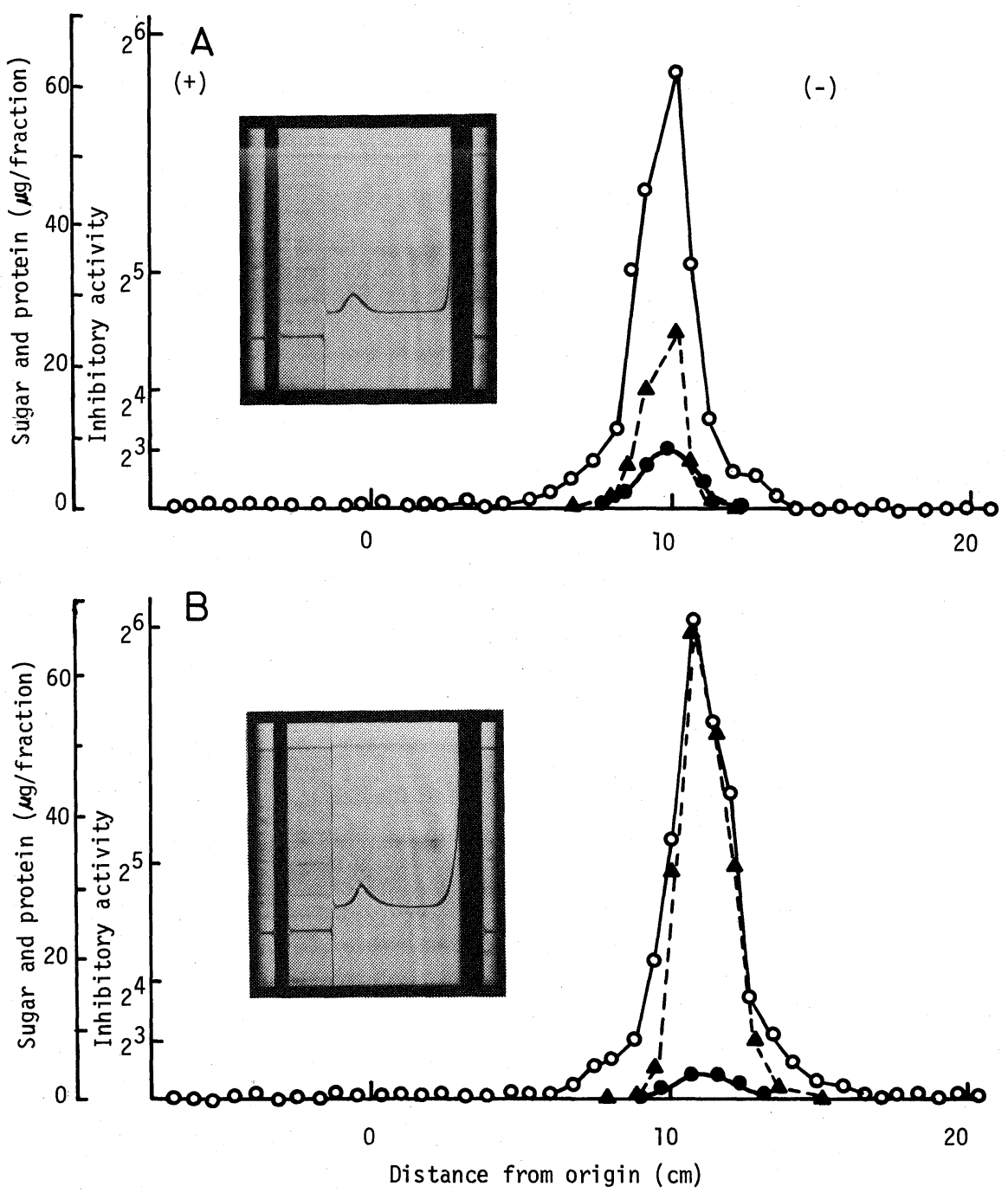

FIG. 2. Electrophoretic and Sedimentation Patterns of Purified Radish AGPs.

Electrophoresis on a glass fiber paper was conducted with $60 \mathrm{~mm}$ borate buffer, $\mathrm{pH} 9.5$, at 1,500 V for $30 \mathrm{~min}$. (A) Run of R-I, 1 mg. (B) R-II, 1 mg. $\bigcirc-\bigcirc$, sugar; - - protein; $\mathbf{\Delta}----\Delta$, serological activity. The insets show sedimentation patterns for each AGP. The samples $\left(1 \%\right.$ in water) were analyzed at $60,000 \mathrm{rpm}$ at $20^{\circ} \mathrm{C}$. The photographs were taken after $32 \mathrm{~min}$.

together with signals at $\delta 4.58\left(0.6 \mathrm{H}, J_{1,2} 8 \mathrm{~Hz}\right)$ and $5.20\left(0.4 \mathrm{H}, J_{1,2}\right.$ low) corresponding to anomeric protons of $\beta$ - and $\alpha$-uronic acids. A portion $(3 \mathrm{mg})$ was converted to the methyl glycoside methyl ester by heating with methanolic hydrogen chloride for $2 \mathrm{hr}$ at $80^{\circ} \mathrm{C}$, neutralized $\left(\mathrm{Ag}_{2} \mathrm{CO}_{3}\right)$, and dried in vacuo. It was dissolved in tetrahydrofuran $(1 \mathrm{ml})$, added dropwise with stirring to $\mathrm{LiAlH}_{4}(10 \mathrm{mg})$ sus- pended in tetrahydrofuran $(0.5 \mathrm{ml})$, heated for $50 \mathrm{~min}$ at $55^{\circ} \mathrm{C}$, cooled, and the excess hydride decomposed with ethyl acetate. After addition of water and centrifugation, the supernatant was deionized, concentrated, and hydrolyzed by heating with $2 \mathrm{M}$ trifluoroacetic acid for $4 \mathrm{hr}$ at $100^{\circ} \mathrm{C}$. PC analysis of the hydrolyzate indicated that the sugar spot, having $R_{\mathrm{Glc}} 1.60$ with solvent A, might correspond to 4-O- 
methyl-D-glucose. A portion of the hydrolysis product was reduced with $\mathrm{NaBD}_{4}$, acetylated, and analyzed by GLC on a $3 \%$ ECNSS-M column, which gave a peak $T_{\mathrm{Glc}}$ (relative to the alditol acetate of D-glucose) of 0.85. MS analysis revealed fragment peaks, $m / z 189,262$, characteristic of 1 (D), 2, 3, 5, 6-penta- $O$ acetyl-4- $O$-methyl hexitol. Another portion of the reduced uronic acid derivative was dissolved in dichloromethane and demethylated by the addition of boron trichloride at $-70^{\circ} \mathrm{C}^{18)}$ Glucose was detected as the demethylated product on PC. From the above data, the major uronic acid of the AGPs was identified as 4- $O$-methyl-D-glucuronic acid (ref. 19; $\left.[\alpha]_{D}+36^{\circ}\right)$.

\section{Properties of AGPs}

Table II summarizes the physical properties, chemical compositions, and hemagglutination inhibition activities of five cruciferous AGPs. The apparent molecular weights of the AGPs were estimated on a Sepharose CL-6B column to range from 0.5 to $1.5 \times 10^{5}$. Of the two turnip AGPs, the neutral component, B-I, was highly heterogeneous and composed of polydisperse molecular species. The carbohydrate compositions of the AGPs closely resembled each other except for B-I; the molar ratios of monosaccharide constituents were confined within the range of $0.1 \sim 0.2$ for L-fucose, $1.5 \sim 2.0$ for $\mathrm{D}$-galactose and $0.1 \sim 0.4$ for the uronic acids when the moles of L-arabinose in each polysaccharide were taken as unity. Estimation of the L-fucose content by the enzymatic method gave values of 4.2, 5.6, and $4.9 \%(\mathrm{w} / \mathrm{w})$ for $\mathrm{R}-\mathrm{I}, \mathrm{R}-\mathrm{II}$, and $\mathrm{B}-\mathrm{N}$, respectively, which were comparable with those obtained colorimetrically and from GLC analysis of the respective AGPs (3.8, 5.9, and 3.3\%).

Data for amino acid analyses of the radish and rape AGPs are listed in Table III. The polypeptide portions of these glycoconjugates had similar unusual amino acid compositions characterized by an abundance of hydroxyproline, serine, threonine, and alanine, and scarcity of arginine, histidine, cystine, phenylalanine, and tyrosine. Hydroxyproline in the hydrolyzates was confirmed on the chromatograms by the formation of a specific red-purple spot with ninhydrin-isatin reagent, and the contents of hydroxyproline in R-I, R-II, and B-N were estimated colorimetrically to be $30.0,8.3$, and $14.4 \mu \mathrm{g} / \mathrm{mg}$ of AGP, respectively. These values coincided well with those obtained by amino acid analysis: 37.0 (R-I), 8.0 (RII), and $12.7 \mu \mathrm{g} / \mathrm{mg}(\mathrm{B}-\mathrm{N})$. Small peaks corresponding to hexosamines were detected in

Table II. Physical Properties, Chemical Compositions, and Hemagglutination InHIBITING ACtivities of Cruciferous AGPs

\begin{tabular}{|c|c|c|c|c|c|}
\hline & \multicolumn{2}{|c|}{ Radish } & \multicolumn{2}{|c|}{ Turnip } & \multirow{2}{*}{$\frac{\text { Rape }}{\text { B-N }}$} \\
\hline & R-I & R-II & B-I & B-II & \\
\hline Molecular weight $\left(\times 10^{5}\right)$ & 1.3 & 0.75 & $0.4 \sim 1.5$ & 0.8 & 0.5 \\
\hline$s_{20 . \mathrm{w}}(\mathrm{S})$ & 3.6 & 2.7 & & & 5.0 \\
\hline$[\alpha]_{D}^{20}$ (degrees) & -47.1 & -52.5 & -12.0 & -41.0 & -52.0 \\
\hline Kjeldahl N ( $\%)$ & 1.46 & 0.77 & 0.73 & 0.49 & 0.63 \\
\hline Total carbohydrate content $(\%)$ & 91.2 & 97.5 & 29.5 & 48.2 & 90.3 \\
\hline \multicolumn{6}{|l|}{ Carbohydrate composition $\left(\mathrm{mol}^{\circ} \mathrm{o}\right)$} \\
\hline L-Fucose & 4.2 & 6.0 & 4.3 & 2.2 & 3.6 \\
\hline L-Arabinose & 28.3 & 28.7 & 72.0 & 38.1 & 38.3 \\
\hline D-Galactose & 55.8 & 59.6 & 22.4 & 57.0 & 52.6 \\
\hline D-Xylose & n.d. & n.d. & 1.3 & n.d. & n.d. \\
\hline Uronic acids & 11.7 & 5.7 & n.d. & 2.7 & 5.5 \\
\hline $\begin{array}{l}\text { Hemagglutination inhibiting } \\
\text { activity }(\mu \mathrm{g} / \mathrm{ml})\end{array}$ & 10 & 5 & 5 & 20 & 10 \\
\hline
\end{tabular}

n.d. $=$ not detected 
Table III. Amino Acid Compositions of RADISH AND RAPE AGPs (mol\%)

\begin{tabular}{lcccc} 
& \multicolumn{2}{c}{ Radish } & & Rape \\
\cline { 2 - 3 } \cline { 5 - 5 } Amino acid & R-I & R-II & & B-N \\
\hline Lysine & 0.9 & 1.3 & & 1.6 \\
Histidine & n.d. & n.d. & & n.d. \\
Arginine & n.d. & n.d. & & n.d. \\
Hydroxyproline & 28.9 & 22.1 & & 25.7 \\
Aspartic acid & 2.8 & 2.9 & & 3.5 \\
Threonine & 8.4 & 11.0 & & 9.1 \\
Serine & 14.8 & 14.4 & & 14.6 \\
Glutamic acid & 3.4 & 9.4 & & 8.3 \\
Proline & 7.2 & 4.8 & & 4.8 \\
Glycine & 5.8 & 5.5 & & 5.4 \\
Alanine & 10.7 & 17.7 & & 13.4 \\
1/2 Cystine & n.d. & n.d. & & n.d. \\
Valine & 2.7 & 5.7 & & 4.0 \\
Methionine & 12.5 & 1.6 & & 6.7 \\
Isoleucine & 0.5 & 1.2 & & 0.6 \\
Leucine & 1.4 & 2.4 & & 2.3 \\
Tyrosine & n.d. & n.d. & n.d. \\
Phenylalanine & n.d. & n.d. & n.d. \\
Total & 100 & 100 & 100 \\
Amino acid content & 10.0 & 2.7 & & 3.8 \\
(\% of total weight) & & & \\
\hline
\end{tabular}

n.d. $=$ not detected

the amino acid analyses: glucosamine content, $0.07,0.16$, and $0.27 \%$ for the AGP R-I, R-II, and $\mathrm{B}-\mathrm{N}$, and galactosamine content, $0.22 \%$ for B-N. However, full identification of these components not yet been accomplished.

\section{Serological properties of $A G P S$}

With five purified AGPs, the minimum amounts required for complete inhibition of the hemagglutination of human $\mathrm{O}$ erythrocytes were found to be in the range of $5 \sim 20 \mu \mathrm{g} / \mathrm{ml}$ when eel anti-H agglutinin (titer $1: 8$ ) was used (Table II). No inhibitory activities were found against chicken anti- $\mathrm{H}$, human anti-A and anti-B antisera, and anti-H lectin of $U$. europeus in the five AGPs even when examined at concentrations above $5 \mathrm{mg} / \mathrm{ml}$.

\section{DISCUSSION}

Following the discovery of polysaccharides with high blood group $\mathrm{H}$-activity in some higher plants by Springer et al., ${ }^{1,2)}$ serologically A-, B-, and $\mathrm{H}$-like substances have been found to be distributed in a wide variety of plants. $^{4 \sim 6,8)}$ Our search on H-like materials cross-reacting with eel anti-H agglutinin in the family Cruciferae indicated the presence of a high activity in buffered hot-water extracts from leaves of the radish, turnip, ${ }^{8)}$ and rape. The purified preparations, R-I, R-II, and B-N, were demonstrated to be high-molecularweight $\left(0.5\right.$ to $\left.1.5 \times 10^{5}\right)$ materials consisting of large amounts (90 to $98 \%$ ) of carbohydrate and small portions (3 to $10 \%$ ) of protein moieties. The AGPs R-I, R-II, B-II, and B-N isolated from cruciferous plants had common sugar constituents, rich in L-arabinose and Dgalactose, and small amounts of $L$-fucose and uronic acids. One of the turnip specimens (BI) passed through a DEAE-cellulose column was free from uronic acid and had xylose as an additional sugar component, but the possibility of contamination with xylose-containing polysaccharides in this fraction could not be excluded because of its polydispersity on gel filtration. The amino acid compositions of the radish and rape AGPs were similar to each other, having abundant hydroxyproline, serine, threonine, and alanine, which represented two-thirds of the protein moieties. Based on the coincident behaviors on electrophoreses, it seems probable that the carbohydrate and protein portions are linked covalently. The chemical and physical properties of these glycoconjugates resembled those of the AGPs which are widely distributed in plant tissues, such as seeds, leaves, roots, and suspensioncultured cells, although the L-fucose found in the cruciferous preparations has been shown to be a rare sugar component of AGPs. ${ }^{20 \sim 22)}$ Arabinogalactans and AGPs have been subclassified into two main group: arabino-4galactans (Aspinall's Type I), which are contained in the primary cell walls of plant tissues; and arabino-3,6-galactans (Type II), which are present in water-soluble hemicellulose fract ions. ${ }^{23,24)}$ Being readily extractable with hotwater from leaf tissues and having a high solubility in water, the cruciferous glycocon- 
jugates would appear to possess the characters of Type II, the arabino-3,6-galactans. The yield of purified radish AGPs, for both R-I and R-II, was $0.13 \%$ of the orginal dry weight of leaves and agreed with the usual values of the order of $0.1 \%$ (dry basis) for the arabinogalactans from most leaf and seed tissues. ${ }^{21)}$

The cruciferous AGPs showed high hemagglutination inhibition activity against eel anti$\mathrm{H}$ agglutinin in the range of 5 to $20 \mu \mathrm{g} / \mathrm{ml}$, which were as high as those found in other purified H-like polysaccharides, such as from Euonymus Sieboldiana seeds $\left(8 \sim 60 \mu \mathrm{g} / \mathrm{ml}^{5}{ }^{5}\right)$ and from twigs of $T$. cuspidata and $S$. albidum (2 $\sim \mu \mathrm{g} / \mathrm{ml}$ when assayed with 4 doses of eel anti-H agglutinin. ${ }^{2,25)}$ ) But these cruciferous AGPs might not be classified as traditional $\mathrm{H}$ substances because they failed to inhibit the hemagglutination of chicken anti-H serum and anti-H lectin of $U$. europeus which are usually used for typing group $\mathrm{H}$ substances. The $\mathrm{H}$ active substances from $T$. cuspidata and $S$. albidum are entirely distinguishable from cruciferous AGPs since both are highly complex polysaccharides comprising rhamnose, xylose, glucose or galacturonic acid in addition to galactose, arabinose and their respective immunodeterminative sugars, and lacking the protein portion. ${ }^{1,2)}$ However, they are known to afford serological specificity similar to the cruciferous AGPs, with a high H-activity only toward eel anti-H agglutinin, but not toward anti-H lectin of Lotus tetragonolobus seeds and human anti-H serum. ${ }^{2,25}$ The serological specificities of eel anti-H agglutinin have been investigated sufficiently and it was found to react with L-fucose and its methylated derivatives, and methylated $\mathrm{D}$-fucose and $\mathrm{D}$ galactose derivatives. $^{3,25,26)}$ It seems probable therefore that the L-fucosyl residues in cruciferous AGPs represent an essential serological determinative group for $\mathrm{H}$-like activity. However, elucidation of the locations of the Lfucosyl residues in the AGP molecules must await further investigation.

Acknowledgments. We wish to thank Professor T. Nakajima, Institute for Medical and Dental Engineering, Tokyo Medical and Dental University (Tokyo), for analyzing the ${ }^{1} \mathrm{H}-\mathrm{NMR}$ spectrum, and $\mathrm{Mr}$. H. Takemoto, Institute of Life Science, Toyo Soda Manufacturing Co., Ltd. (Yamaguchi), for carring out the GLC-MS spectrometry. We are also indebted to Mr. M. Chijimatsu, The Institute of Physical and Chemical Research (Saitama), for the ultracentrifugal analyses.

\section{REFERENCES}

1) G. F. Springer, Naturwissenschaften, 43, 256 (1956).

2) G. F. Springer, T. Takahashi, P. R. Desai and B. J. Kolecki, Biochemistry, 4, 2099 (1965).

3) G. F. Springer and P. Williamson, Biochem. J., 85, 282 (1962).

4) S. Yamamoto, J. Immunogenet., 2, 197 (1975).

5) S. Yamamoto, I. Sakai and S. Iseki, Immunological Commun., 10, 215 (1981).

6) S. Yamamoto, J. Immunogenet., 4, 325 (1977).

7) S. Yamamoto, Vox Sang., 30, 220 (1976).

8) S. Yamamoto, Agric. Biol. Chem., 46, 1971 (1982).

9) H. Schachter, J. Sarney, E. J. McGuire and S. Roseman, J. Biol. Chem., 244, 4785 (1969).

10) M. Dubois, K. A. Gilles, J. K. Hamilton, P. A. Rebers and F. Smith, Anal. Chem., 28, 350 (1956).

11) J. T. Galambos, Anal. Biochem., 19, 119 (1967).

12) O. H. Lowry, N. J. Rosebrough, A. L. Farr and R. J. Randall, J. Biol. Chem., 193, 265 (1951).

13) W. E. Trevelyan, D. P. Procter and J. S. Harrison, Nature, 166, 444 (1950).

14) L. Hough, J. K. N. Jones and W. H. Wadman, $J$. Chem. Soc., 1702 (1950).

15) N. Blumenkrantz and G. Asboe-Hansen, Anal. Chem., 55, 288 (1973).

16) M. G. Kollor and H. R. Roberts, Arch. Biochem. Biophys., 70, 620 (1957).

17) Y. Sone, M. Kakuta and A. Misaki, Agric. Biol. Chem., 42, 417 (1978).

18) S. Allen, T. G. Bonner, E. J. Bourne and N. M. Saville, Chem. Ind., 630 (1958).

19) D. M. W. Anderson and I. C. M. Dea, Carbohyd. Res., 5, 461 (1967).

20) A. E. Clarke, R. L. Anderson and B. A. Stone, Phytochemistry, 18, 521 (1979).

21) A. E. Clarke, P. A. Gleeson, M. A. Jermyn and R. B. Knox, Aust. J. Plant Physiol., 5, 707 (1978).

22) G. B. Fincher, B. A. Stone and A. E. Clarke, Ann. Rev. Plant Physiol., 34, 47 (1983).

23) G. O. Aspinall, "Biogenesis of Plant Cell Wall Polysaccharides," ed. by F. A. Loewus, Academic Press, New York, 1973, p. 95.

24) P. Albersheim, "Plant Biochemistry," 3rd Ed., ed. by J. Bonner and J. E. Varner, Academic Press, New York, 1976, p. 225.

25) G. F. Springer, P. R. Desai and B. J. Kolecki, Biochemistry, 3, 1076 (1964).

26) G. F. Springer and P. R. Desai, Biochemistry, 10, 3749 (1971). 